not depend on differences in adiposity and are likely to have an environmental basis. Strategies for chronic disease prevention need to include measures to combat the emergence of chronic disease risks in childhood or earlier.

\section{P2-223 THE COMBINED EFFECT OF CHEWING THOROUGHLY AND EATING UNTIL FULL ON CHILDHOOD OVERWEIGHT: RESULTS OF 1999-2009 SCHOOL-BASED SURVEY IN JAPAN}

doi:10.1136/jech.2011.142976j.56

${ }^{1} \mathrm{H}$ Ochiai, ${ }^{1} \mathrm{~T}$ Shirasawa, ${ }^{1} \mathrm{~N}$ Shimada, ${ }^{2} \mathrm{R}$ Nishimura, ${ }^{2} \mathrm{~A}$ Morimoto, ${ }^{1} \mathrm{~T}$ Ohtsu, ${ }^{1} \mathrm{H}$ Hoshino, ${ }^{1} \mathrm{~A}$ Kokaze. ${ }^{1}$ Department of Public Health, Showa University School of Medicine, Tokyo, Japan; ${ }^{2}$ Division of Diabetes, Metabolism and Endocrinology, Department of Internal Medicine, Jikei University School of Medicine, Tokyo, Japan

Introduction The aim of the present study was to investigate the relationship of overweight to chewing thoroughly and eating until full and to examine the combined effect of chewing thoroughly and eating until full on overweight among schoolchildren in Japan.

Methods Subjects included all fourth-grade schoolchildren (9 or 10 years of age) in Ina-town, Saitama prefecture, Japan, during 1999-2009. Information about subject's sex, age, and lifestyle, including chewing thoroughly and eating until full, was collected using a self-administered questionnaire. Measurements of height and weight were made for each child. Overweight in children was defined according to the criteria of the International Obesity Task Force. To calculate the OR and 95\% CI for overweight, a logistic regression model was used.

Results Data from 4027 children were analysed. Chewing thoroughly revealed significantly decreased $\mathrm{OR}$ for overweight when compared to not chewing thoroughly (OR: 0.39 , 95\% CI 0.33 to $0.48)$. Eating until full showed significantly increased OR for overweight compared with not eating until full (1.24, 1.02 to 1.51). Among children who reported chewing thoroughly, OR of eating until full was not statistically significant $(0.97,0.76$ to 1.24$)$. On the other hand, eating until full illustrated significantly increased $O R$ among the not chewing thoroughly group $(1.67,1.21$ to 2.30 ).

Conclusion Chewing thoroughly and eating until full were associated with overweight. Furthermore, a combined effect of not chewing thoroughly and eating until full on overweight was noted. This study suggests that chewing thoroughly is useful for the prevention of childhood overweight.

\section{P2-224 PATHWAYS TO DIAGNOSIS DO NOT EXPLAIN ALL OF THE INCREASE IN THYROID CANCER: RESULTS OF A POPULATION BASED CROSS-SECTIONAL STUDY}

\section{doi:10.1136/jech.2011.142976j.57}

${ }^{1} \mathrm{D}$ O'Connell, ${ }^{*} \mathrm{C}$ Kahn, ${ }^{1,2} \mathrm{~L}$ Simonella, ${ }^{2} \mathrm{M}$ Sywak, ${ }^{3} \mathrm{~S}$ Boyages, ${ }^{4} \mathrm{O}$ Ung. ${ }^{1} \mathrm{Cancer}$ Council NSW, Sydney, New South Wales, Australia; ${ }^{2}$ University of Sydney, Sydney, New South Wales, Australia; ${ }^{3}$ Clinical Education and Training Institute NSW, Westmead, New South Wales, Australia; ${ }^{4}$ Royal Brisbane and Women's Hospital, Brisbane, Queensland, Australia

Background The incidence of thyroid cancer has increased over the last few decades in many countries, particularly in developed countries and markedly in the Australian state of New South Wales (NSW). To investigate whether these changes may be due to increased detection we studied the clinical pathways leading to the diagnosis of thyroid cancer.

Methods Newly diagnosed cases of thyroid cancer were identified and recruited through the population-based NSW Central Cancer
Registry. Participants completed a questionnaire and diary of doctor visits and investigations that led to their diagnosis. Tumour characteristics were obtained from pathology reports.

Results 452 people (76\% female) with thyroid cancer completed the study. The median age at diagnosis was 48 years for women and 53 for men. Only $40 \%$ of diagnoses occurred after the patient reported a lump or symptom and $60 \%$ of diagnoses were serendipitous. The pathways to diagnosis varied significantly with tumour size $(p=0.001)$ and by age in men $(p=0.008)$ and place of residence in women $(p=0.05)$. Not all of the increase in incidence is explained by increased detection. Allowing for cases diagnosed serendipitously, the estimated age-standardised incidence rates for men (3.83 per $100000)$ and women (10.65 per 100000$)$ were well below those observed (4.65 and 15.3 respectively).

Conclusion As the diagnosis of only $40 \%$ of thyroid cancers was patient initiated, the reported incidence of thyroid cancer is likely to be influenced by diagnostic technology and medical surveillance practices. This, however, probably only partly explains the observed rise in incidence of thyroid cancer in NSW.

\section{P2-225 PROSTATE-SPECIFIC ANTIGEN TESTING AWARENESS AND PARTICIPATION IN NEW SOUTH WALES, AUSTRALIA: DEMOGRAPHIC, LIFESTYLE AND HEALTH-RELATED FACTORS}

doi:10.1136/jech.2011.142976j.58

${ }^{1} \mathrm{D}$ O'Connell, ${ }^{*} \mathrm{~L}$ Carmichael, ${ }^{1} \mathrm{D}$ Smith, ${ }^{2} \mathrm{M}$ Gattellari, ${ }^{3} \mathrm{~S}$ Chambers, ${ }^{4} \mathrm{C}$ Pinnock, ${ }^{5}$ T Slevin, ${ }^{6} \mathrm{~J}$ Ward. ${ }^{1}$ Cancer Council NSW, Sydney, New South Wales, Australia; ${ }^{2}$ University of NSW, Sydney, New South Wales, Australia; ${ }^{3}$ Griffith University, Brisbane, Queensland, Australia; ${ }^{4}$ Repatriation General Hospital, Daws Park, South Australia, Australia; ${ }^{5}$ Cancer Council WA, Perth, Western Australia, Australia; ${ }^{6}$ University of Ottawa, Ottawa, Ontario, Canada

Background Although the prostate-specific antigen (PSA) test is widely used to screen for prostate cancer, there is very little information on the characteristics of men who are aware of the PSA test, and their patterns of PSA testing.

Methods A cross-sectional study used computer assisted telephone interviews to collect data in New South Wales, Australia. Multinomial logistic regression identified the factors independently associated with the awareness of, and participation in PSA testing.

Results Of the 6100 men, 39\% were unaware of the PSA test, $12 \%$ were aware of the PSA test but never tested, 14\% had a non-recent PSA test, and $35 \%$ had a recent PSA test. Unaware men were more likely to be born outside Australia ( $\mathrm{OR}=1.19 ; 95 \%$ CI 0.88 to 1.60$)$, have a blue-collar occupation ( $\mathrm{OR}=1.38 ; 95 \% \mathrm{CI} 1.00$ to 1.91$)$, be a current smoker $(\mathrm{OR}=1.99$; $95 \% \mathrm{CI} 1.30$ to 3.05$)$, or have benign prostatic hyperplasia (BPH) $(\mathrm{OR}=1.70 ; 95 \% \mathrm{CI} 1.07$ to 2.71$)$, and less likely to have completed a higher school certificate $(\mathrm{OR}=0.44$ $95 \%$ CI 0.24 to 0.79 ), or live in inner regional areas (OR $=0.59 ; 95 \%$ CI 0.44 to 0.80$)$. Men who did not have a recent test, were more likely to visit the doctor $(\mathrm{OR}=1.38 ; 95 \%$ CI 1.05 to 1.82$)$, or have $\mathrm{BPH}(\mathrm{OR}=2.70 ; 95 \% \mathrm{CI} 1.74$ to 4.20$)$, and were less unsure of their risk of developing prostate cancer $(\mathrm{OR}=0.61 ; 95 \% \mathrm{CI} 0.37$ to 1.00$)$. Men who had a recent test were more likely to visit the doctor $(\mathrm{OR}=2.57 ; 95 \%$ CI 1.99 to 3.33), have $\mathrm{BPH}(\mathrm{OR}=3.87 ; 95 \%$ CI 2.58 to 5.81 ), or have a higher perceived risk of developing prostate cancer $(\mathrm{OR}=1.99 ; 95 \% \mathrm{CI} 1.22$ to 3.26$)$, and less likely to be other than married (OR $=0.65 ; 95 \%$ CI 0.47 to 0.91 ).

Conclusions As men's PSA testing experience varied by demographic, lifestyle and health-related factors, it is important for policymakers and physicians to consider these when communicating about PSA testing. 